\title{
Anaesthesia for reduction of anterior dislocations of the shoulder
}

Sir,

Further to Mr A. Banerjee's letter to your journal regarding the requirement of anaesthesia for reduction of anterior dislocations of the shoulder, while agreeing with him that anaesthesia is not necessary for the majority of patients, I would like to point out that in the original description by Theodore Kocher published in 1881 there is no mention of traction during the manoeuvre.

In fact, Kocher describes flexion at the elbow with the arm parallel to the chest, lateral rotation of the humerus, flexion at the shoulder, adduction and lastly internal rotation. He claimed that anterior sub-coracoid dislocation of the shoulder can be reduced without either assistants or anaesthesia, provided that neither the glenoid rim nor the greater tuberosity were fractured and that capsular damage was not so extensive that the bone surfaces were not held apposed. In our department we have used Kochers method without anaesthesia or analgesia for 42 consecutive anterior subcoracoid dislocations of the shoulder since August 1990 with a success rate of 40 out of 42 . The two failures were due to undiagnosed greater tuberosity fracture, and subsequently required general anaesthesia.

\section{R. JEYARAJAN \& A. R. COPE}

Department of Accident and Emergency Medicine

Peterborough District Hospital

Peterborough

\section{Pharyngeal perforation: an unusual complication of fish bone impaction}

Sir,

I wish to report an unusual complication of fish bone impaction, in order to emphasize the life threatening situation that may develop when these foreign bodies are missed. A 15-year-old boy presented 5 days after eating cod with a swelling in the right side of his neck. He was pyrexial and there was a marked torticollis to the right. On examination the fishbone was easily palpable overlying the thyroid cartilage. He had been seen in casualty only hours after the impaction but the diagnosis was not made. He was discharged without any radiological investigations and he was not advised to reattend if the sensation did not resolve.

The clinical impression of a fishbone having migrated from the pyriform fossa through the thyrohyoid membrane was confirmed by radiology (Fig. 1). At operation a fishbone measuring $1.2 \mathrm{~cm}$ was found just deep to the platysma. He was treated intensively and made a full recovery.

It must be emphasized that early perforation can occur with an impacted foreign body and further migration may take place later. Early investigation is essential. The fauces should be examined and a mirror examination of the pharynx performed. A lateral soft tissue neck radiograph should be requested only if a full clinical examination fails to reveal the site of the bone. The interpretation of these films is hampered by the presence of larygneal calcification which is invariably present in the elderly but is now known to affect $40 \%$ of older teenagers 


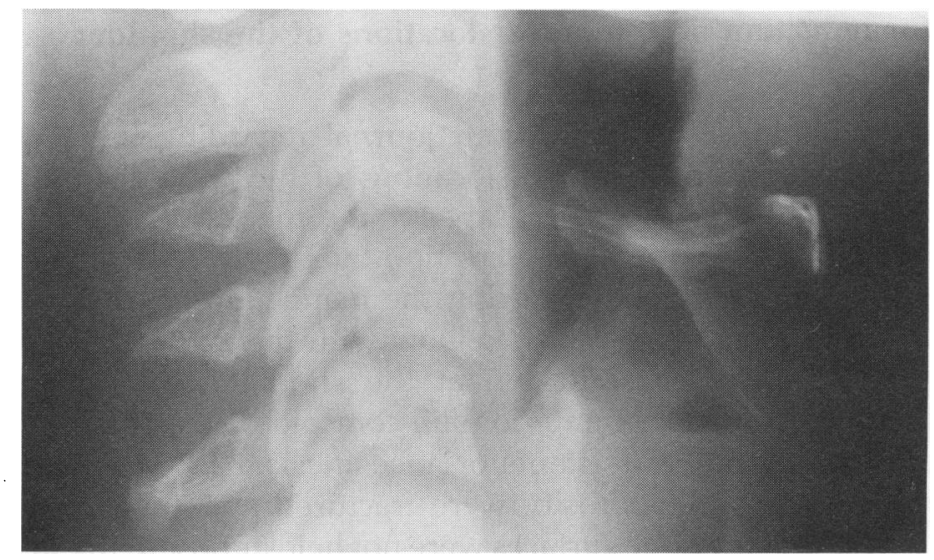

Fig. 1. Radiograph showing fishbone.

(Hately et al., 1965). The other factor which causes confusion is the debatable radio-opacity of bones from various fish. Ell (1989) recently looked at this problem by placing small bones from 10 commonly available fish in uncooked chicken legs and assessing their visibility on plain radiographs. He found that small Mackerel and Herring bones could not be seen on plain radiographs. All other bones were clearly seen.

If no abnormality is found on mirror examination and plain radiology fails to⿳亠二口犬 reveal any evidence of a foreign body then it is highly likely that the injury is no? more than a superficial mucosal abrasion. Unless one suspects that the bone has impacted below the area seen on a lateral neck X-ray then it is reasonable to discharge the patient. It is important to advise the patient to reattend if the discomfort persists or if there is a deterioration in the symptoms. An E.N.T. opinion is necessary if any abnormality is found or if any doubt exists in the mind of an inexperienced clinician.

G. O'SULLIVAN

Department of Otorhinolaryngology

Royal Liverpool Hospital

Liverpool

\section{REFERENCES}

Ell S. R. (1989) Radio-opacity of fishbones. Journal of Laryngology and Otology 103, 1224-1226.

Hately W. Evison G. \& Samuel E. (1965) The pattern of ossification in the laryngeal cartilages: A radiological study. British Journal of Radiology 38, 585-591. 